\title{
Influence of leaching parameters on the vanadium extraction from petroleum coke
}

\author{
A.A. Kudinova, N.K. Kondrasheva, and V.A. Rudko \\ Department of Chemical Technology and Energy Processing, Faculty of Mineral Raw Materials \\ Processing, Saint Petersburg Mining University, Saint Petersburg, Russia
}

\begin{abstract}
More than 60 trace elements, including rare metals, can be found in heavy oils. The most valuable component of oils and petroleum products is vanadium. It is used as an alloying agent to create extra strong steel, as a cathode for lithium-ion batteries, and also as a catalyst in the chemical industry. Nowadays studies of various methods for extracting vanadium from heavy oils and petroleum products are actively carried out. This work presents the method of alkaline and acid leaching of vanadium from petroleum coke and also results of the examination of influence of factors such as the duration of the process $(0.5,1.5$ and $2.5 \mathrm{~h})$ and the ratio of solid and liquid phases (1:2,1:3 and 1:4). The highest yield of vanadium $80 \%$ is observed using sulfuric acid with the process duration is 1.5 hours and the ratio $\mathrm{S} / \mathrm{L}=1: 4$
\end{abstract}

\section{Introduction}

In connection with the depletion of light oil reserves, the question of processing of heavy metal oils arose [1]. However, the metals contained in oils adversely affect the quality of the obtained products, deactivate catalysts for oil refining processes, and cause corrosion of the equipment[2-4]. At the same time, trace elements are contained in oils are valuable incidental components, of which vanadium is an important strategic metal, due to it use as an alloying additive to high-strength steel, a cathode for lithium-ion batteries, catalysts, etc.[5].

Vanadium is the single element that is currently extracted from heavy oils, but only abroad. This is due to the fact that the content of vanadium in heavy oils is comparable or higher than its content in the ores from which it is extracted. Therefore, the process of extracting vanadium from oil can become more cost effective, and it can also provide products for metallurgical production because its demand for vanadium is constantly growing[4]. In addition, extraction of vanadium in the form of porphyrin complexes by extractive methods is also important for the petrochemical industry [6-8].

About $95 \%$ of all vanadium amount gets concentrated in petroleum coke during the coking process $[9,10]$, so it a promising raw material for the recovery of vanadium. Spent catalysts and ash from boilers of thermoelectric power plants using fuel oil and petroleum coke can also serve as raw materials for vanadium recovery. A large number of studies have been carried outon the extraction of vanadium using ash from thermal power plants as a raw material [11-16] and few research is devoted the study of coke as a raw material for the recovery of vanadium $[17,18]$. 
V.A. Rudko [17] studied the influence of the ratio of the solid (coke) to the liquid (acid) phase, as well as the time of the process on the yield of vanadium in the process of acid leaching. To carry out the process, petroleum coke was ground to a particle size of $100 \mu \mathrm{m}$. Concentrated and diluted sulfuric acid and a mixture of concentrated nitric and sulfuric acids in a 1:1 mass ratio were used as leaching agents. It was shown that with a decrease in the ratio of the solid and liquid phases from 1:3 to $3: 1$, the degree of extraction of vanadium also decreases.

M.R. Tavakoli [18] studied the leaching process using vanadium pent oxide as the raw material. Sulfuric acid and sodium hydroxide were used as leaching agents. It was shown that a decrease in the $\mathrm{pH}$ and temperature of the process for acid leaching leads to an increase in the solubility of vanadium. The opposite data was obtained for alkaline leaching. Moreover, the solubility of vanadium in sulfuric acid solution was found to be higher than in solutions of nitric and hydrochloric acids. This is due to the formation of a complex of the vanadylion with sulfate.

Y.L. Zhang [19] studied the effect of sodium sulfate on the leaching process. Prior to the experiment, the coke was ground and sieved to the particle size range of $74 \mu \mathrm{m}$. It was shown that a small amount of sodium sulfate (about $0.7 \mathrm{~g}$ ) increases the leaching rate.

Thermodynamic calculations show that it is most advantageous to carry out the leaching process with a dilute sodium hydroxide solution as a reagent in order to extract vanadium. However, according to experimental data, the highest yield of vanadium is obtained when using concentrated sulfuric acid. This discrepancy between calculations and experimental data can be explained by the influence of factors that thermodynamics does not take into account, for example, the difference in the passage of the reagent into the pores of the coke.

Thereby, in this work, we compared the effect of acid and alkali agents on the extraction of vanadium from petroleum coke by the leaching method. We used different parameters of the process, such as the ratio of liquid and solid phases and the duration of the process, to the compare the vanadium recovery from petroleum coke.

\section{Experimental}

\subsection{Materials}

An industrially obtained sample of petroleum coke from a mixture of West Siberian oils was taken from a delayed coking unit.

The main technological parameters of the delayed coking process were:

- Coking temperature at the reactor's inlet: $505^{\circ} \mathrm{C}$

- Coking pressure in the reactor: $0.35 \mathrm{MPa}$ (excessive)

- The load factor for raw materials: 1.2.

The materials balance of the delayed coking process is presented in Table 1:

Table 1. The materials balance of the delayed coking process.

\begin{tabular}{cc|cc}
\hline Input & \multicolumn{2}{c}{ Output } \\
\hline Atmospheric residue & 85.0 & Gas & 5.4 \\
HGOCC & & Petrol & 9.8 \\
& 15.0 & Lightgasoil & 28.5 \\
& & Heavy gasoil & 29.9 \\
& & Coke & 27.3 \\
\hline Total: & $\mathbf{1 0 0 . 0}$ & Total: & $\mathbf{1 0 0 . 0}$ \\
\hline
\end{tabular}

*HGOCC - stands for heavy gasoil catalytic cracking

Quality indicators of petroleum coke are indicated below.

- The yield of volatile substances: $7.8 \%$ 
- Ash content: $0.11 \%$

- Content, \%, of other components: S - 1.6911, V - 0.0198, Si - 0.0010, Fe - 0.0009.

\subsection{Leaching of vanadium from petroleum coke}

Experiments on the leaching of vanadium from petroleum coke were carried out in stainless steel reactors $60 \mathrm{~mm}$ high and of $40 \times 30 \mathrm{~mm}$ in diameter. Each reactor was charged with $1 \mathrm{~g}$ of petroleum coke (particle size of about $0.1 \mathrm{~mm}$ ) and the necessary amount of leaching agent (acids or alkali) were placed in each reactor. Then the reactors were placed in a drying oven and kept at the temperature of $100{ }^{\circ} \mathrm{C}$ from 0.5 to 2.5 hours.

$\mathrm{NaOH} 10 \%$ and $\mathrm{H}_{2} \mathrm{SO}_{4} 12 \%$ were used as leaching agents. Acid or alkali was added to the coke so that the ratio of solid and liquid $(\mathrm{S} / \mathrm{L})$ phases was 1:2, 1:3 and 1:4.

After the leaching process petroleum coke was filtered using a "white tape" filter paper and washed with $30-40 \mathrm{ml}$ of water. Then it was dried in a drying oven at the temperature of $110^{\circ} \mathrm{C}$ to constant weight.

\subsection{Photometric analysis of the solutions after leaching}

Analysis of the solutions after leaching was carried out using a PE-5400 UV spectrophotometer (LLC "ECROSCHIM"). The degree of vanadium extraction from petroleum coke was determined according to GOST 10364 "Oil and petroleum products. Vanadium determination method."

$40 \mathrm{ml}$ of the solution after leaching, $2 \mathrm{ml}$ of diluted sulfuric acid 1:1, $5 \mathrm{ml}$ of diluted phosphoric acid, and $2.5 \mathrm{ml}$ of sodium tungstate solution were placed in a $100 \mathrm{ml}$ beaker. After adding each reagent, the contents of the beaker were mixed by shaking. The resulting solution was heated to $40-70{ }^{\circ} \mathrm{C}$ and then cooled down to room temperature. Then the solution was quantitatively transferred into a $50 \mathrm{ml}$ volumetric flask and adjusted to the mark with distilled water. The solution was left for 60 minutes.

A control solution was prepared for photometric analysis. $2 \mathrm{ml}$ of sulfuric acid 1:1, $5 \mathrm{ml}$ of diluted phosphoric acid, and $2.5 \mathrm{ml}$ of sodium tungstate solution were placed in a $50 \mathrm{ml}$ flask. The resulting solution was adjusted to the mark with distilled water. The optical density of the solution after leaching was determined relative to the control solution. The mass of vanadium in $\mathrm{mg}$ contained in $50 \mathrm{ml}$ of the solution was determined according to the calibration plot (Figure 1).

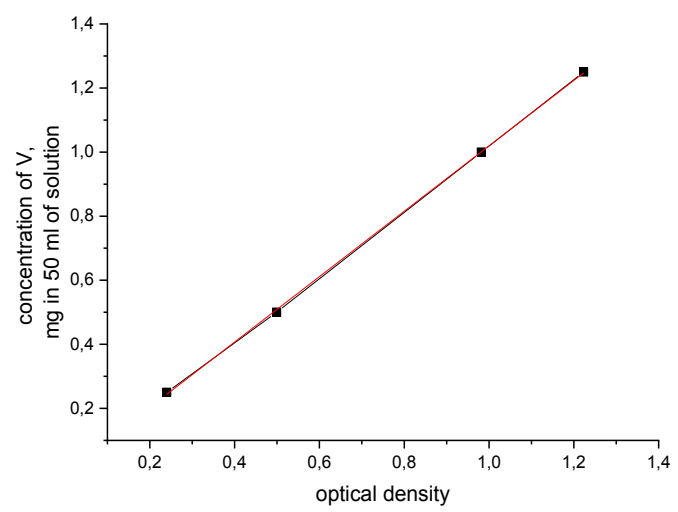

Fig. 1. Calibration plot for determining the content of vanadium in the solution. 
The concentration of vanadium in $\mathrm{mg}$ per $\mathrm{kg}$ of raw material is calculated by Equation (1):

$$
\mathrm{C}=\frac{m_{1} \cdot 1000 \cdot 50}{m \cdot V}
$$

where $\mathrm{m}_{1}$ - is the mass of vanadium in the solution, determined according to the calibration plot, $\mathrm{mg} ; \mathrm{m}$ - is the sample weight, $\mathrm{g} ; 50$ - is the volume of solution made for photometric analysis, $\mathrm{ml} ; \mathrm{V}-$ is the aliquot of the solution taken for photometry analysis, $\mathrm{ml}$.

The degree of extraction of vanadium from petroleum coke in the leaching process is determined by Equation (2):

$$
E=\frac{c}{C_{\text {coke }}} \cdot 100 \%
$$

where $\mathrm{C}-$ is the concentration of vanadium in solution, $\mathrm{mg} / \mathrm{kg} ; \mathrm{C}_{\text {coke }}-$ is the concentration of vanadium in petroleum coke, $\mathrm{mg} / \mathrm{kg}$.

\subsection{X-ray fluorescence analysis}

The content of sulfur and trace elements in the obtained samples of petroleum coke was determined using X-ray fluorescence spectrometry without preliminary ashing of the samples using the addition method on a sequential wave dispersive X-ray fluorescence spectrometer XRF-1800 Shimadzu[20,21]. The device is equipped with an X-ray tube with an anode of Rh with a power of $2.7 \mathrm{~kW}$. A detailed method for the determination of sulfur and trace elements is described in [22].

\subsection{Derivatographic analysis}

Thermogravimetric analysis and differential scanning calorimetry were performed on a SDT Q600 thermal analyzer. This device allows to conduct these analyzes simultaneously, which significantly reduces the time spent on examining samples. The sample weight for analysis was taken with an accuracy of $10^{-3} \mathrm{mg}$. The mass of carbon material was taken in the range from $15.494 \mathrm{mg}$ to $5.406 \mathrm{mg}$. Heating was carried out from 50 to $1000{ }^{\circ} \mathrm{C}$ at a rate of $20^{\circ} \mathrm{C} / \mathrm{min}$. The oxidizing environment was the air.

\subsection{X-ray diffraction analysis}

X-ray diffraction analysis of samples of carbon materials was carried out using aXRD-7000 Shimadzu X-ray diffractometer $(\mathrm{CuK} \alpha$ radiation, $2.7 \mathrm{~kW})$ at room temperature using the polycrystal method. Radiographs were taken at large accumulation times (2 s) and a scanning step of $0.02^{\circ}$.

The asymmetric reflections of petroleum cokes were decomposed into peaks. Their profile is described by a Gaussian with a maximum at angles of $2 \theta$ characterizing certain structural components of the samples.

In this work, we used the inter-planar distance of the (002) and (110) diffraction maxima, as well as the sizes of the coherent scattering region in the directions of the axes "c" (average crystallite height $\mathrm{L}_{c}$ ) and "a" (average diameter of hexagonal layers $\mathrm{L}_{\mathrm{a}}$ ) for a detailed assessment of the fine structure of carbon materials by the X-ray diffraction method. The inter-planar distance $\left(\mathrm{d}_{002}\right.$ and $\left.\mathrm{d}_{110}\right)$ in $\AA$ of the obtained samples of petroleum coke was calculated according to the Wulf-Bragg equation [23,24]: 


$$
d=\frac{\lambda}{2 \cdot \sin \theta},
$$

where $\lambda=1.5406$ - is the X-ray wavelength for $\mathrm{CuK} \alpha, \AA ; \theta$ - is the Bragg diffraction angle, rad.

The average linear size of crystallites $\mathrm{L}_{c}$ and $\mathrm{L}_{\mathrm{a}}$ was determined in $\AA$ according to the Scherrer Equation [25]:

$$
L_{c}=\frac{0.89 \cdot \lambda}{\beta_{002} \cdot \cos \theta_{002}} \text { and } L_{a}=\frac{0.89 \cdot \lambda}{\beta_{110} \cdot \cos \theta_{110}},
$$

where 0.89 - is the Scherer constant, which for cokes was conditionally set the same for the uniformity in the published results [26]; $\beta$ - is the width of the diffraction line at half the maximum height (in rad) minus the hardware peak width $b=0.2^{\circ}$.

\section{Results and discussion}

\subsection{Leaching and analysis of product solutions}

The degree of vanadium extraction was determined according to paragraph 2.3. The optical density of the solution was recalculated to the degree of extraction using Equations 1 and 2. The received data are presented in Table 2.

\begin{tabular}{|c|c|c|c|c|c|c|c|}
\hline $\begin{array}{c}\text { Time, } \\
\mathrm{h}\end{array}$ & Leaching agent & $\mathrm{S} / \mathrm{L}$ & $\begin{array}{l}\text { Optical } \\
\text { density }\end{array}$ & $\begin{array}{c}\text { Mass } \\
\text { of } \\
\text { coke, } \\
\text { g }\end{array}$ & $\begin{array}{l}\text { Concentration } \\
\text { of } \mathrm{V}, \mathrm{mg} \text { in } \\
50 \mathrm{ml} \text { of } \\
\text { solution }\end{array}$ & $\begin{array}{c}\text { Concentration } \\
\text { of } \mathrm{V}, \mathrm{mg} / \mathrm{kg}\end{array}$ & $\begin{array}{c}\text { Degree of } \\
\text { extraction, } \\
\%\end{array}$ \\
\hline \multirow{6}{*}{0.5} & \multirow{3}{*}{$\mathrm{H}_{2} \mathrm{SO}_{4}$} & $1: 2$ & 0.091 & 1.0035 & 0.092 & 115 & 55 \\
\hline & & $1: 3$ & 0.107 & 1.0082 & 0.108 & 134 & 64 \\
\hline & & $1: 4$ & 0.101 & 1.0089 & 0.102 & 127 & 60 \\
\hline & \multirow{3}{*}{$\mathrm{NaOH}$} & $1: 2$ & 0.068 & 1.0018 & 0.068 & 85 & 40 \\
\hline & & $1: 3$ & 0.074 & 1.0066 & 0.075 & 93 & 44 \\
\hline & & $1: 4$ & 0.096 & 1.0007 & 0.097 & 121 & 58 \\
\hline \multirow{6}{*}{1.5} & \multirow{3}{*}{$\mathrm{H}_{2} \mathrm{SO}_{4}$} & $1: 2$ & 0.065 & 1.0013 & 0.065 & 81 & 39 \\
\hline & & $1: 3$ & 0.082 & 1.0060 & 0.083 & 103 & 49 \\
\hline & & $1: 4$ & 0.134 & 1.0016 & 0.135 & 169 & 80 \\
\hline & \multirow{3}{*}{$\mathrm{NaOH}$} & $1: 2$ & 0.090 & 1.0078 & 0.091 & 113 & 54 \\
\hline & & $1: 3$ & 0.088 & 1.0094 & 0.089 & 110 & 52 \\
\hline & & $1: 4$ & 0.119 & 1.0018 & 0.121 & 151 & 72 \\
\hline \multirow{6}{*}{2.5} & \multirow{3}{*}{$\mathrm{H}_{2} \mathrm{SO}_{4}$} & $1: 2$ & 0.079 & 1.0033 & 0.079 & 99 & 47 \\
\hline & & $1: 3$ & 0.087 & 1.0043 & 0.088 & 110 & 52 \\
\hline & & $1: 4$ & 0.092 & 1.0064 & 0.093 & 116 & 55 \\
\hline & \multirow{3}{*}{$\mathrm{NaOH}$} & $1: 2$ & 0.065 & 1.0040 & 0.065 & 81 & 39 \\
\hline & & $1: 3$ & 0.112 & 1.0027 & 0.113 & 141 & 67 \\
\hline & & $1: 4$ & 0.063 & 1.0016 & 0.063 & 79 & 38 \\
\hline
\end{tabular}

Table 2. The degree of vanadium extraction.

Earlier in our laboratory it was shown that from the point of view of thermodynamics, sodium hydroxide is the best leaching agent. However, as can be seen from Table 1, the recovery of vanadium is higher when sulfuric acid is used. This is due to the fact that, in addition to thermodynamic factors, other parameters influence the leaching process, such as pore size, reagent diffusion, etc. 
The recovery of vanadium increases with an increase in the $\mathrm{S} / \mathrm{L}$ ratio and the duration of the process, if sodium hydroxide or dilute sulfuric acid are used as a leaching agent. However, if the process is carried out for 2.5 hours, the degree of extraction decreases; that is also described in the works $[11,14]$. This may be due to the predominance of adverse and substitution reactions, whereby solubility of vanadium decreases.

The highest recovery of vanadium $(80 \%)$ is observed in the leaching process in the presence of sulfuric acid for 1.5 hours with a phase ratio of 1:4. The maximum of vanadium recovery for sodium hydroxide $(72 \%)$ is observed under the same conditions. Thus, the maximum of vanadium recovery can be obtained by carrying out the process for 1.5 hours at a phase ratio of 1:4.

The spent solution after the alkylation of isobutene with olefins can be used like sulfuric acid as leaching agent in production [27].

\subsection{Analysis of the composition and structure of the carbon residue after leaching}

\subsubsection{X-ray fluorescence analysis}

The composition of the solid residue after leaching was studied by X-ray fluorescence analysis. The obtained data are presented in Table 3.

Table 3.The composition of the solid residue after leaching.

\begin{tabular}{|c|c|c|c|c|c|c|c|c|}
\hline \multirow{2}{*}{ Time,h } & \multirow{2}{*}{$\begin{array}{l}\text { Leaching } \\
\text { agent }\end{array}$} & \multirow{2}{*}{$\mathrm{S} / \mathrm{L}$} & \multicolumn{6}{|c|}{ Content of element, $\%$} \\
\hline & & & V & $\mathrm{Ni}$ & $\mathrm{S}$ & $\mathrm{Fe}$ & $\mathrm{Al}$ & $\mathrm{Ca}$ \\
\hline \multirow{6}{*}{0.5} & \multirow{3}{*}{$\mathrm{H}_{2} \mathrm{SO}_{4}$} & $1: 2$ & 0.0095 & 0.0100 & 1.9119 & 0.0259 & 0.0046 & 0.0041 \\
\hline & & $1: 3$ & 0.0076 & 0.0171 & 1.3976 & 0.0189 & 0.0049 & 0.0033 \\
\hline & & $1: 4$ & 0.0083 & 0.0114 & 1.8702 & 0.0360 & 0.0056 & 0.0260 \\
\hline & \multirow{3}{*}{$\mathrm{NaOH}$} & $1: 2$ & 0.0125 & 0.0155 & 1.8826 & 0.0484 & 0.0131 & 0.0096 \\
\hline & & $1: 3$ & 0.0117 & 0.0130 & 1.8980 & 0.0286 & 0.0180 & 0.0107 \\
\hline & & $1: 4$ & 0.0089 & 0.0094 & 1.6805 & 0.0270 & 0.0857 & 0.0246 \\
\hline \multirow{6}{*}{1.5} & \multirow{3}{*}{$\mathrm{H}_{2} \mathrm{SO}_{4}$} & $1: 2$ & 0.0129 & 0.0144 & 2.8792 & 0.0408 & 0.0074 & 0.0183 \\
\hline & & $1: 3$ & 0.0107 & 0.0126 & 1.9173 & 0.0198 & 0.0061 & 0.0040 \\
\hline & & $1: 4$ & 0.0041 & 0.0150 & 0.9374 & 0.0366 & 0.0028 & 0.0046 \\
\hline & \multirow{3}{*}{$\mathrm{NaOH}$} & $1: 2$ & 0.0097 & 0.0113 & 1.8730 & 0.0222 & 0.0041 & 0.0139 \\
\hline & & $1: 3$ & 0.0100 & 0.0134 & 1.8198 & 0.0167 & 0.0043 & 0.0122 \\
\hline & & $1: 4$ & 0.0059 & 0.0185 & 1.1460 & 0.0269 & 0.0026 & 0.0083 \\
\hline \multirow{6}{*}{2.5} & \multirow{3}{*}{$\mathrm{H}_{2} \mathrm{SO}_{4}$} & $1: 2$ & 0.0111 & 0.0118 & 1.9178 & 0.0174 & 0.0051 & 0.0048 \\
\hline & & $1: 3$ & 0.0100 & 0.0117 & 1.8670 & 0.0404 & 0.0059 & 0.0129 \\
\hline & & $1: 4$ & 0.0094 & 0.0097 & 1.8843 & 0.0308 & 0.0044 & 0.0068 \\
\hline & \multirow{3}{*}{$\mathrm{NaOH}$} & $1: 2$ & 0.0129 & 0.0138 & 1.8251 & 0.0220 & 0.0051 & 0.0084 \\
\hline & & $1: 3$ & 0.0069 & 0.0090 & 1.3881 & 0.0530 & 0.0050 & 0.0141 \\
\hline & & $1: 4$ & 0.0131 & 0.0145 & 1.8110 & 0.0190 & 0.0046 & 0.0079 \\
\hline
\end{tabular}

As can be seen from the table, the sulfur content is higher in the samples obtained by leaching in the presence of sulfuric acid. Sulfur is a more harmful impurity than vanadium, therefore the sodium hydroxide is better to use for improving the quality of coke obtained after leaching.

The content of aluminum and calcium is higher in the samples obtained using sodium hydroxide, so alkali has a higher selectivity for the extraction of vanadium compared to acid. 


\subsubsection{Derivatographic analysis}

The chemical reactions taking place in the solid residue after the leaching process with increasing temperature were studied by the method of thermogravimetry (Figure 2). Two processes are noticeable on the obtained curves: decomposition of the carbon part $\left(600^{\circ} \mathrm{C}\right)$ and oxidation $\left(400^{\circ} \mathrm{C}\right)$.

The mass of the samples for the study was not constant, therefore, to compare the oxidation state, the increase in the mass of the sample in percent was calculated using Equation 5:

$$
M=\frac{m_{0 x}}{m_{\text {sam }}} \cdot 100 \%
$$

where $\mathrm{M}$ - is the sample weight increase, $\% ; \mathrm{m}_{\mathrm{ox}}-$ is the maximum mass of the sample after oxidation, $\mathrm{mg} ; \mathrm{m}_{\mathrm{sam}}$ - is the sample weight taken for research, $\mathrm{mg}$.

Table 4 presents the data calculated according to Equation 5.
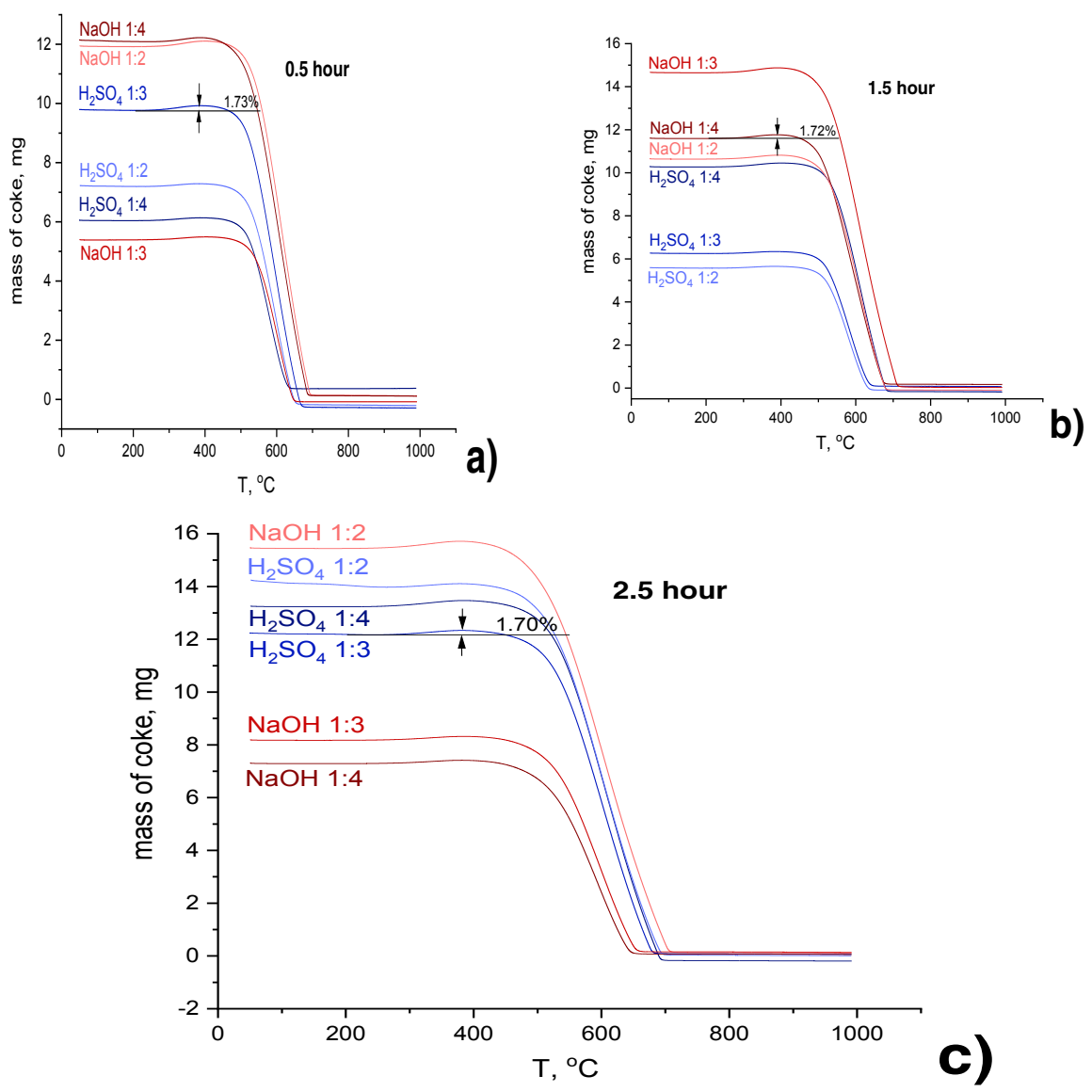

Fig. 2. Thermo gravimetric analysis: the duration of the process is a) 0.5 hours, b) 1.5 hours, c) 2.5 hours. 
Table 4. The results of thermogravimetric analysis.

\begin{tabular}{|c|c|c|c|c|c|}
\hline Time, $\mathrm{h}$ & $\begin{array}{c}\text { Leaching } \\
\text { agent }\end{array}$ & $\mathrm{S} / \mathrm{L}$ & $\begin{array}{l}\text { Mass of samples, } \\
\text { mg }\end{array}$ & $\begin{array}{c}\text { Maximum mass } \\
\text { after oxidation, } \\
\mathrm{mg}\end{array}$ & $\begin{array}{c}\text { Increase massof } \\
\text { samples, } \%\end{array}$ \\
\hline \multirow{6}{*}{0.5} & \multirow{3}{*}{$\mathrm{H}_{2} \mathrm{SO}_{4}$} & $1: 2$ & 7.252 & 0.10 & 1.38 \\
\hline & & $1: 3$ & 9.833 & 0.17 & 1.73 \\
\hline & & $1: 4$ & 6.074 & 0.10 & 1.65 \\
\hline & \multirow{3}{*}{$\mathrm{NaOH}$} & $1: 2$ & 11.960 & 0.17 & 1.42 \\
\hline & & $1: 3$ & 5.406 & 0.10 & 1.85 \\
\hline & & $1: 4$ & 12.165 & 0.14 & 1.15 \\
\hline \multirow{6}{*}{1.5} & \multirow{3}{*}{$\mathrm{H}_{2} \mathrm{SO}_{4}$} & $1: 2$ & 5.615 & 0.07 & 1.25 \\
\hline & & $1: 3$ & 6.293 & 0.07 & 1.11 \\
\hline & & $1: 4$ & 10.316 & 0.22 & 2.13 \\
\hline & \multirow{3}{*}{$\mathrm{NaOH}$} & $1: 2$ & 10.683 & 0.18 & 1.68 \\
\hline & & $1: 3$ & 14.698 & 0.22 & 1.50 \\
\hline & & $1: 4$ & 11.639 & 0.20 & 1.72 \\
\hline \multirow{6}{*}{2.5} & \multirow{3}{*}{$\mathrm{H}_{2} \mathrm{SO}_{4}$} & $1: 2$ & 14.343 & 0.14 & 0.98 \\
\hline & & $1: 3$ & 12.329 & 0.21 & 1.70 \\
\hline & & $1: 4$ & 13.281 & 0.24 & 1.81 \\
\hline & \multirow{3}{*}{$\mathrm{NaOH}$} & $1: 2$ & 15.494 & 0.27 & 1.74 \\
\hline & & $1: 3$ & 8.199 & 0.14 & 1.71 \\
\hline & & $1: 4$ & 7.326 & 0.14 & 1.91 \\
\hline
\end{tabular}

The mass of the samples obtained using sodium hydroxide increases more than for the samples obtained using sulfuric acid. This fact confirms the previous conclusion about the higher selectivity of sodium hydroxide for the vanadium extraction as compared to sulfuric acid. This is due to the fact that sulfur and metals, remaining in the samples after leaching, are subjected to oxidation[28,29]. The more metals and sulfur are left in the sample, the more its mass will increase during the oxidation process.

More oxidation is observed in the samples in the presence of sulfuric acid, when the ratio of solid and liquid phases is 1:4. This may be due to an increase of the sulfur content in these samples. The fact that the sulfur content in these samples is higher than in the samples obtained using alkali was shown in section 3.2.1.

The curves that were obtained by the method of differential scanning calorimetry (DSC) show one peak corresponding to the decomposition of the sample. There are no peaks corresponding to oxidation, because the oxidation process only affects $2 \%$ of the total mass and has little effect on the overall heat balance of the system (Figure 3 ). 
a)
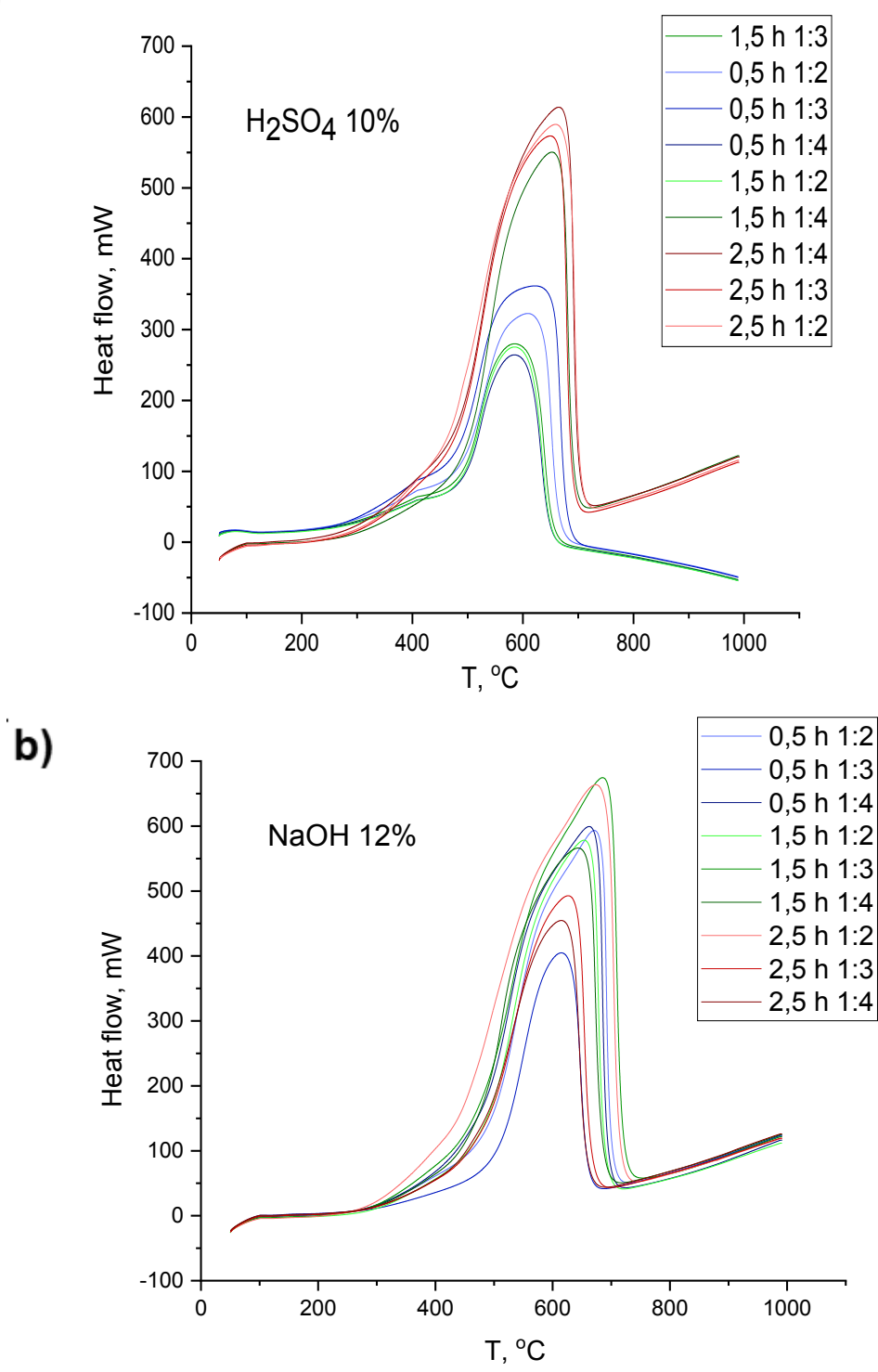

Fig. 3. DSC curves for samples were obtained using $\mathrm{NaOH}$ (a) and $\mathrm{H}_{2} \mathrm{SO}_{4}$ (b).

The average decomposition temperature of the sample was calculated according to the DSC curves. Table 5 presents the obtained data.

The decomposition temperature of the sample is $640{ }^{\circ} \mathrm{C}$.

Table 5. Decomposition temperatures of samples.

\begin{tabular}{cccc}
\hline Time, $\mathrm{h}$ & Leaching agent & $\mathrm{S} / \mathrm{L}$ & $\begin{array}{c}\text { Decomposition } \\
\text { temperature, }{ }^{\circ} \mathrm{C}\end{array}$ \\
\hline \multirow{2}{*}{0.5} & $\mathrm{H}_{2} \mathrm{SO}_{4}$ & $1: 2$ & 609 \\
& & $1: 3$ & 622 \\
& & $1: 4$ & 584 \\
\cline { 2 - 4 } & $\mathrm{NaOH}$ & $1: 2$ & 671 \\
\hline
\end{tabular}




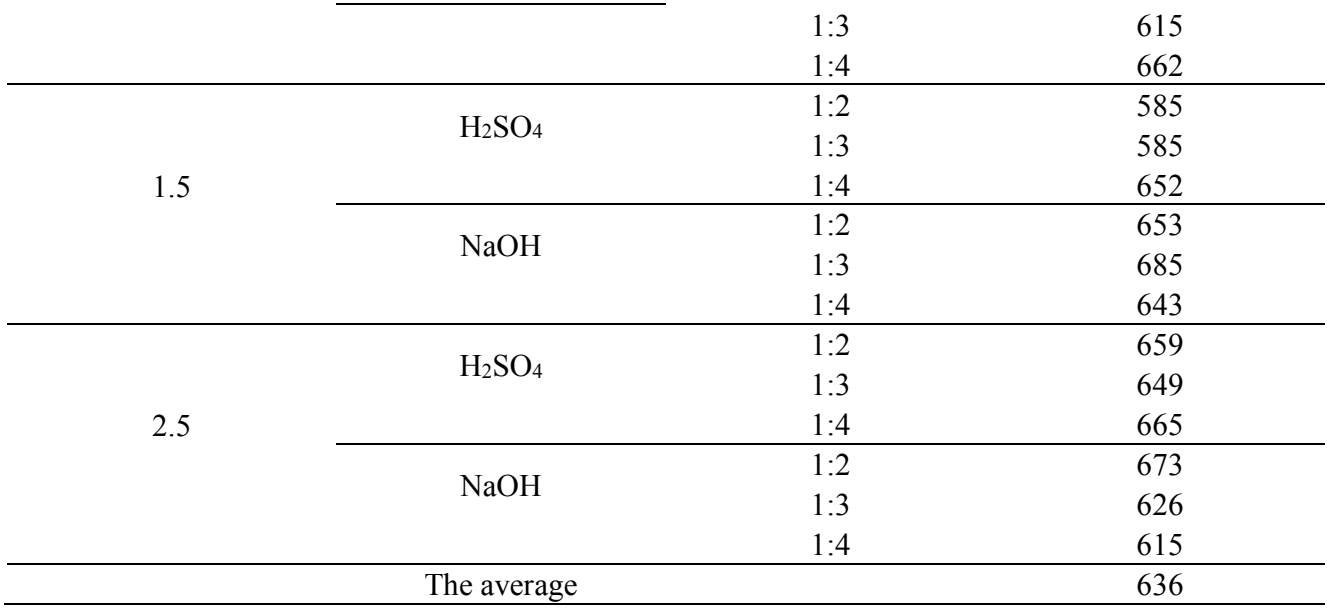

\subsubsection{X-ray diffraction analysis}

Petroleum coke is amorphous carbon with a low degree of crystallinity. Amorphous carbon transforms into graphite during high-temperature processing. Crystallites formed in the amorphous matrix of petroleum coke during the thermolysis have a turbostract structure that differs from the graphite one [30]. The main structural parameters of such crystals are the inter-planar distances $d_{002}, d_{110}$ and the sizes of the coherent scattering regions in the direction of the crystallographic axes "c" and "a", $\mathrm{L}_{\mathrm{c}}$ and $\mathrm{L}_{\mathrm{a}}$, respectively. For graphite, $\mathrm{d}_{002}$ and $\mathrm{d}_{110}$ are 3.354 and $1.232 \AA$, respectively, and for a turbostratic structure, $\mathrm{d}_{002}$ varies from 3.37 to $3.60 \AA$, and $\mathrm{d}_{110}$ from 1.215 to $1.230 \AA$ [31].

a)

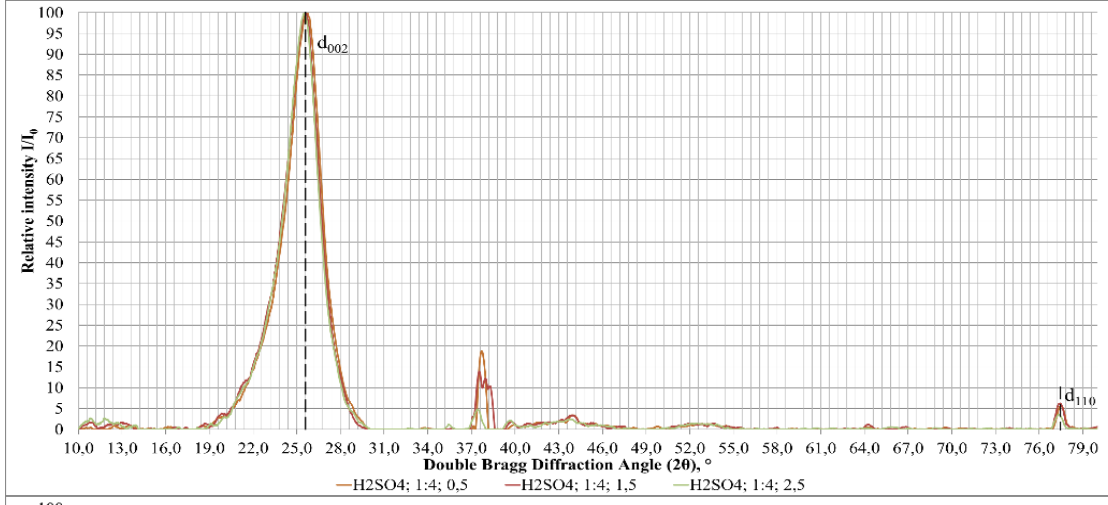

b)

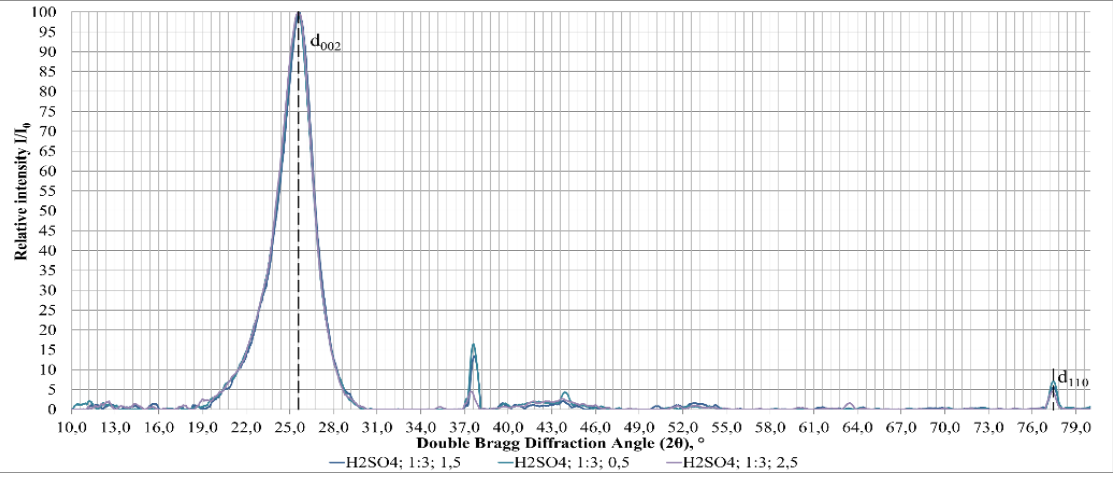


c)

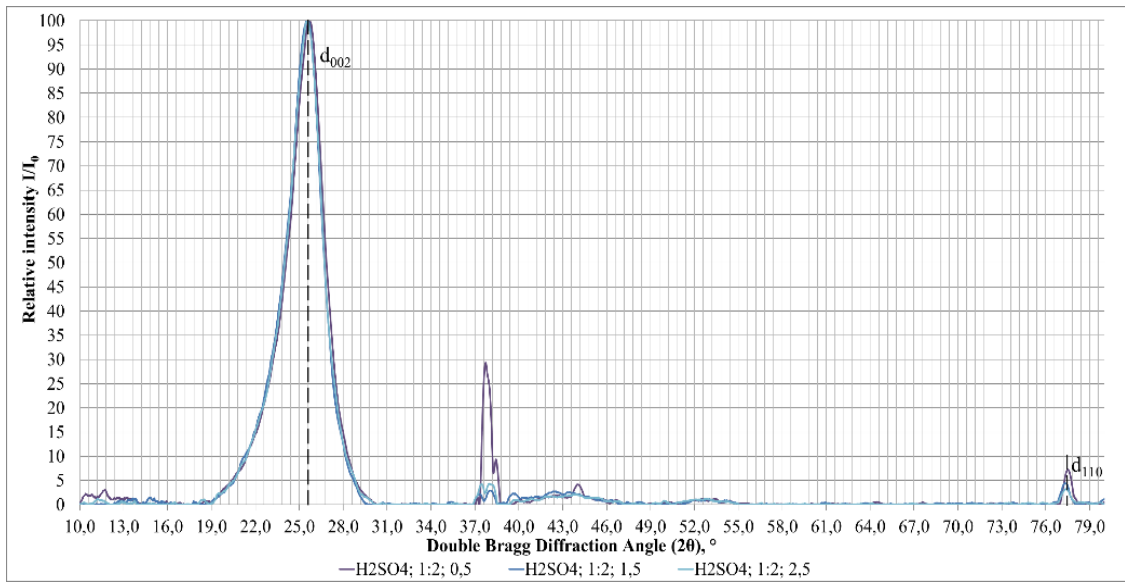

Fig. 4. Comparison of the diffraction patterns of the carbon material after vanadium recovery in presence of $\mathrm{H}_{2} \mathrm{SO}_{4}$ at $0.5,1.5$ and $2.5 \mathrm{~h}:$ a) $\mathrm{S}: \mathrm{L}=1: 4$; b) $\mathrm{S}: \mathrm{L}=1: 3$; c) $\mathrm{S}: \mathrm{L}=1: 2$.

Figures 4 and 5 show a comparison of the diffractograms of the carbon material after the leaching process in the presence of $\mathrm{H}_{2} \mathrm{SO}_{4}$ and $\mathrm{NaOH}$, respectively.

a)

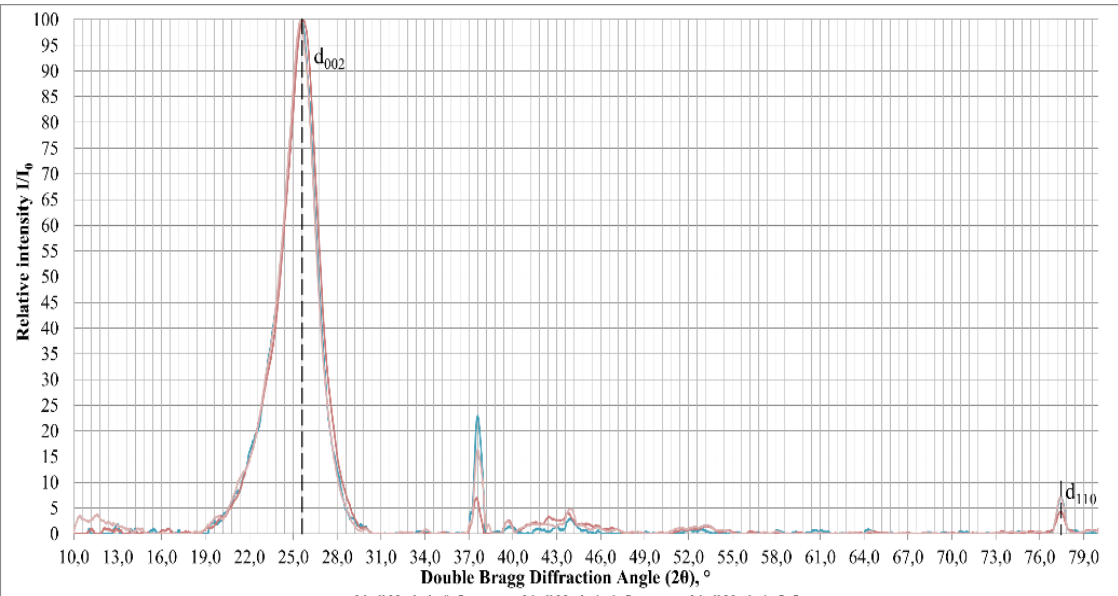

b)

$-\mathrm{NaOH} ; 1: 4 ; 0,5 \quad-\mathrm{NaOH} ; 1: 4 ; 1,5 \quad-\mathrm{NaOH} ; 1: 4 ; 2,5$

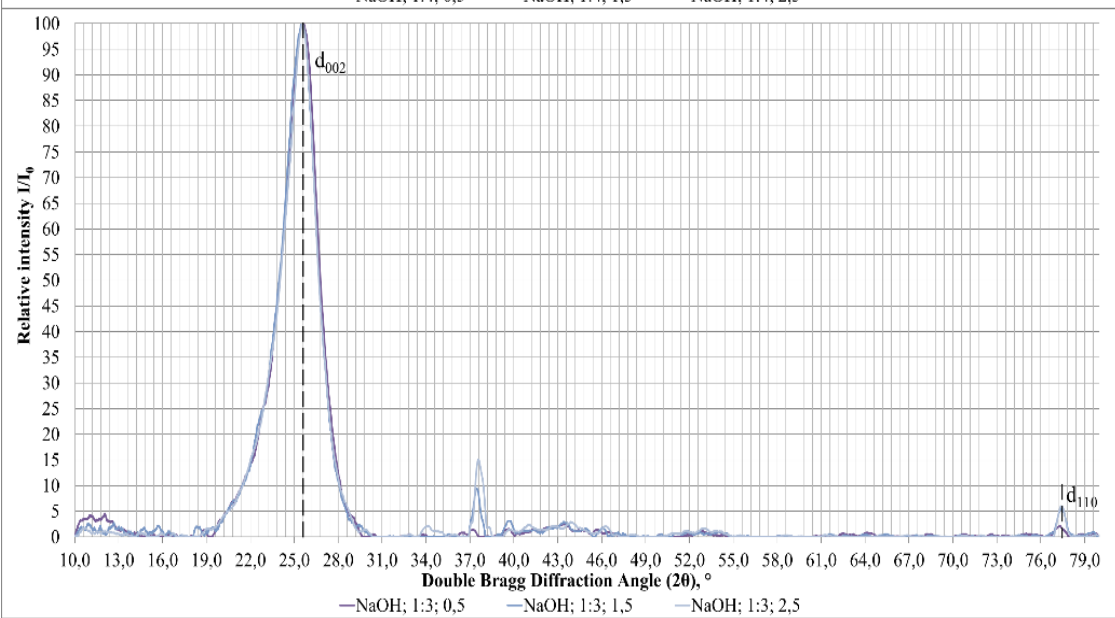


c)

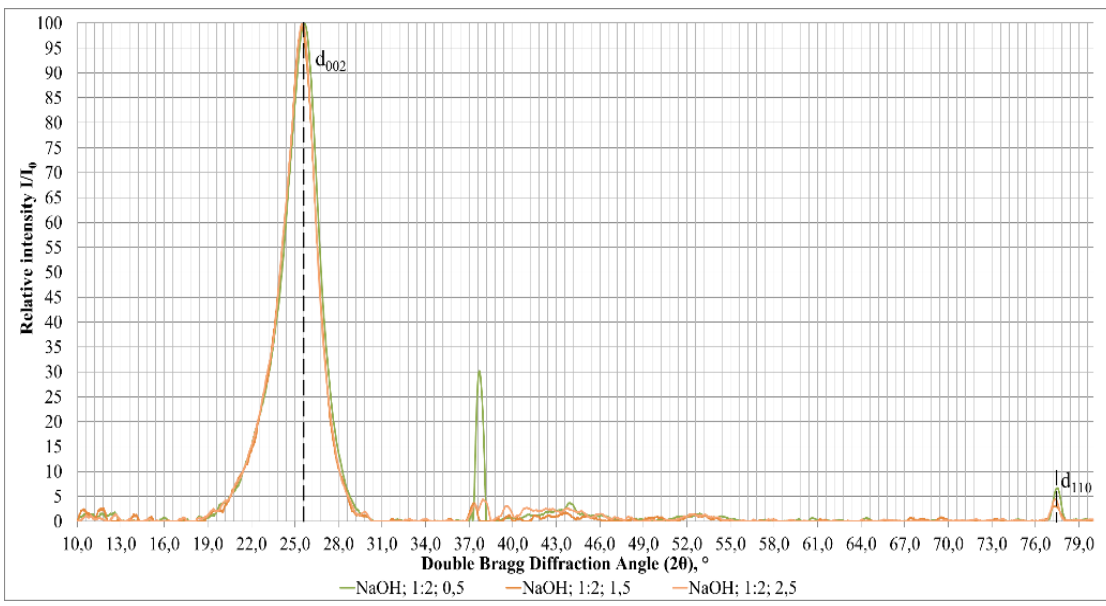

Fig. 5. Comparison of the diffraction patterns of the carbon material after vanadium recovery in presence of $\mathrm{NaOH}$ at $0.5,1.5$ and $2.5 \mathrm{~h}$ : a) $\mathrm{S}: \mathrm{L}=1: 4$; b) $\mathrm{S}: \mathrm{L}=1: 3$; c) $\mathrm{S}: \mathrm{L}=1: 2$.

Peaks with a maximum of $2 \theta$ angles in X-ray diffractograms are about $25^{\circ}$ and $77^{\circ}$, respectively responsible for reflections $2 \theta_{002}$ and $2 \theta_{110}$, are clearly expressed characteristic of petroleum coke. The angular position of the reflexes $\left(2 \theta_{002}\right.$ and $\left.2 \theta_{110}\right)$ in the X-ray diffraction pattern is determined by the corresponding inter-planar distance $\left(\mathrm{d}_{002}\right.$ and $\left.\mathrm{d}_{110}\right)$ [32,33]. The diffractometric analysis results and values calculated from (002) and (110) reflections for the carbon material after vanadium recovery are shown in Table 6.

Table 6. Results of diffractometric analysis of carbon material.

\begin{tabular}{|c|c|c|c|c|c|c|c|c|}
\hline \multirow[b]{2}{*}{$\begin{array}{c}\text { Characteristic } \\
\mathrm{s}\end{array}$} & \multicolumn{4}{|c|}{ Reflex (002) } & \multicolumn{4}{|c|}{ Reflex (110) } \\
\hline & $2 \theta, \circ$ & Halfwidth & $\begin{array}{c}\mathrm{d}_{002}, \\
\AA\end{array}$ & $\mathrm{L}_{\mathfrak{c}}, \AA$ & $2 \theta,^{\circ}$ & Halfwidth & $\begin{array}{c}\mathrm{d}_{110}, \\
\AA\end{array}$ & $\mathrm{L}_{\mathrm{a}}, \AA$ \\
\hline $\begin{array}{c}\mathrm{H}_{2} \mathrm{SO}_{4} ; 1: 3 ; \\
1.5\end{array}$ & $\begin{array}{c}25.60 \\
0 \\
\end{array}$ & 2.6800 & $\begin{array}{c}3.476 \\
9 \\
\end{array}$ & $\begin{array}{c}29.467 \\
2 \\
\end{array}$ & $\begin{array}{c}77.44 \\
0 \\
\end{array}$ & 0.6000 & $\begin{array}{c}1.231 \\
5 \\
\end{array}$ & $\begin{array}{c}173.997 \\
9 \\
\end{array}$ \\
\hline $\begin{array}{c}\mathrm{H}_{2} \mathrm{SO}_{4} ; 1: 2 \\
0.5\end{array}$ & $\begin{array}{c}25.66 \\
0\end{array}$ & 2.7600 & $\begin{array}{c}3.468 \\
9\end{array}$ & $\begin{array}{c}28.611 \\
9\end{array}$ & $\begin{array}{c}77.50 \\
0\end{array}$ & 0.6200 & $\begin{array}{c}1.230 \\
7\end{array}$ & $\begin{array}{c}167.791 \\
5\end{array}$ \\
\hline $\begin{array}{c}\mathrm{H}_{2} \mathrm{SO}_{4} ; 1: 3 ; \\
0.5\end{array}$ & $\begin{array}{c}25.62 \\
0\end{array}$ & 2.7000 & $\begin{array}{c}3.474 \\
2\end{array}$ & $\begin{array}{c}29.248 \\
9\end{array}$ & $\begin{array}{c}77.46 \\
0\end{array}$ & 0.5800 & $\begin{array}{c}1.231 \\
2\end{array}$ & $\begin{array}{c}180.817 \\
6\end{array}$ \\
\hline $\begin{array}{c}\mathrm{H}_{2} \mathrm{SO}_{4} ; 1: 4 \\
0.5\end{array}$ & $\begin{array}{c}25.72 \\
0 \\
\end{array}$ & 2.7400 & $\begin{array}{c}3.460 \\
9 \\
\end{array}$ & $\begin{array}{c}28.825 \\
3 \\
\end{array}$ & $\begin{array}{c}77.48 \\
0 \\
\end{array}$ & 0.6000 & $\begin{array}{c}1.230 \\
9 \\
\end{array}$ & $\begin{array}{c}174.046 \\
7 \\
\end{array}$ \\
\hline $\begin{array}{c}\mathrm{H}_{2} \mathrm{SO}_{4} ; 1: 2 ; \\
1.5\end{array}$ & $\begin{array}{c}25.60 \\
0\end{array}$ & 2.7600 & $\begin{array}{c}3.476 \\
9\end{array}$ & $\begin{array}{c}28.608 \\
5\end{array}$ & $\begin{array}{c}77.30 \\
0\end{array}$ & 0.6600 & $\begin{array}{c}1.233 \\
3\end{array}$ & $\begin{array}{c}156.338 \\
6\end{array}$ \\
\hline $\begin{array}{c}\mathrm{H}_{2} \mathrm{SO}_{4} ; 1: 4 \\
1.5\end{array}$ & $\begin{array}{c}25.60 \\
0\end{array}$ & 2.8000 & $\begin{array}{c}3.476 \\
9\end{array}$ & $\begin{array}{c}28.197 \\
7\end{array}$ & $\begin{array}{c}77.44 \\
0\end{array}$ & 0.6400 & $\begin{array}{c}1.231 \\
5\end{array}$ & $\begin{array}{c}161.902 \\
3\end{array}$ \\
\hline $\begin{array}{c}\mathrm{NaOH} ; 1: 2 \\
0.5\end{array}$ & $\begin{array}{c}25.66 \\
0 \\
\end{array}$ & 2.7000 & $\begin{array}{c}3.468 \\
9 \\
\end{array}$ & $\begin{array}{c}29.251 \\
2 \\
\end{array}$ & $\begin{array}{c}77.52 \\
0 \\
\end{array}$ & 0.6200 & $\begin{array}{c}1.230 \\
4\end{array}$ & $\begin{array}{c}167.815 \\
0\end{array}$ \\
\hline $\begin{array}{c}\mathrm{NaOH} ; 1: 3 ; \\
0.5\end{array}$ & $\begin{array}{c}25.52 \\
0\end{array}$ & 2.7600 & $\begin{array}{c}3.487 \\
6\end{array}$ & $\begin{array}{c}28.604 \\
0\end{array}$ & $\begin{array}{c}77.30 \\
0 \\
\end{array}$ & 0.7000 & $\begin{array}{c}1.233 \\
3\end{array}$ & $\begin{array}{c}146.584 \\
5\end{array}$ \\
\hline $\begin{array}{l}\mathrm{NaOH} ; 1: 4 \\
0.5\end{array}$ & $\begin{array}{c}25.56 \\
0\end{array}$ & 2.7000 & $\begin{array}{c}3.482 \\
2\end{array}$ & $\begin{array}{c}29.245 \\
4\end{array}$ & $\begin{array}{c}77.46 \\
0\end{array}$ & 0.6000 & $\begin{array}{c}1.231 \\
2\end{array}$ & $\begin{array}{c}174.022 \\
3\end{array}$ \\
\hline $\begin{array}{c}\mathrm{NaOH} ; 1: 2 ; \\
1.5\end{array}$ & $\begin{array}{c}25.48 \\
0 \\
\end{array}$ & 2.6600 & $\begin{array}{c}3.493 \\
0 \\
\end{array}$ & $\begin{array}{c}29.682 \\
9 \\
\end{array}$ & $\begin{array}{c}77.32 \\
0 \\
\end{array}$ & 0.7600 & $\begin{array}{c}1.233 \\
1 \\
\end{array}$ & $\begin{array}{c}134.129 \\
8 \\
\end{array}$ \\
\hline $\begin{array}{c}\mathrm{NaOH} ; 1: 3 ; \\
1.5\end{array}$ & $\begin{array}{c}25.48 \\
0 \\
\end{array}$ & 2.7200 & $\begin{array}{c}3.493 \\
0\end{array}$ & $\begin{array}{c}29.024 \\
6\end{array}$ & $\begin{array}{c}77.44 \\
0\end{array}$ & 0.6800 & $\begin{array}{c}1.231 \\
5\end{array}$ & $\begin{array}{c}151.445 \\
8\end{array}$ \\
\hline $\mathrm{NaOH} ; 1: 4$ & 25.70 & 2.8000 & 3.463 & 28.203 & 77.46 & 0.6600 & 1.231 & 156.513 \\
\hline
\end{tabular}




\begin{tabular}{|c|c|c|c|c|c|c|c|c|}
\hline \multirow{2}{*}{$\begin{array}{c}\text { Characteristic } \\
\mathrm{s}\end{array}$} & \multicolumn{4}{|c|}{ Reflex (002) } & \multicolumn{4}{c|}{ Reflex (110) } \\
\cline { 2 - 9 } & $2 \theta,{ }^{\circ}$ & $\begin{array}{c}\text { Halfwidth } \\
\circ\end{array}$ & $\begin{array}{c}\mathrm{d} 002, \\
\AA\end{array}$ & $\mathrm{L}_{\mathrm{c}}, \AA$ & $2 \theta,{ }^{\circ}$ & $\begin{array}{c}\text { Halfwidth } \\
\circ\end{array}$ & $\begin{array}{c}\mathrm{d}_{110}, \\
\AA\end{array}$ & $\mathrm{L}_{\mathrm{a}}, \AA$ \\
\hline 1.5 & 0 & & 6 & 3 & 0 & & 2 & 5 \\
\hline $\begin{array}{c}\mathrm{H}_{2} \mathrm{SO}_{4} ; 1: 4 ; \\
2.5\end{array}$ & $\begin{array}{c}25.54 \\
0\end{array}$ & 2.6400 & $\begin{array}{c}3.484 \\
9\end{array}$ & $\begin{array}{c}29.912 \\
7\end{array}$ & $\begin{array}{c}77.36 \\
0\end{array}$ & 0.6200 & $\begin{array}{c}1.232 \\
5\end{array}$ & $\begin{array}{c}167.627 \\
2\end{array}$ \\
\hline $\begin{array}{c}\mathrm{H}_{2} \mathrm{SO}_{4} ; 1: 3 ; \\
2.5\end{array}$ & $\begin{array}{c}25.58 \\
0\end{array}$ & 2.7400 & $\begin{array}{c}3.479 \\
6\end{array}$ & $\begin{array}{c}28.817 \\
3\end{array}$ & $\begin{array}{c}77.38 \\
0\end{array}$ & 0.6000 & $\begin{array}{c}1.232 \\
3\end{array}$ & $\begin{array}{c}173.925 \\
0\end{array}$ \\
\hline $\begin{array}{c}\mathrm{H}_{2} \mathrm{SO}_{4} ; 1: 2 ; \\
2.5\end{array}$ & $\begin{array}{c}25.54 \\
0\end{array}$ & 2.7200 & $\begin{array}{c}3.484 \\
9\end{array}$ & $\begin{array}{c}29.028 \\
0\end{array}$ & $\begin{array}{c}77.42 \\
0\end{array}$ & 0.7000 & $\begin{array}{c}1.231 \\
7\end{array}$ & $\begin{array}{c}146.707 \\
4\end{array}$ \\
\hline $\begin{array}{c}\mathrm{NaOH} ; 1: 2 ; \\
2.5\end{array}$ & $\begin{array}{c}25.58 \\
0\end{array}$ & 2.6800 & $\begin{array}{c}3.479 \\
6\end{array}$ & $\begin{array}{c}29.466 \\
0\end{array}$ & $\begin{array}{c}77.40 \\
0\end{array}$ & 0.6000 & $\begin{array}{c}1.232 \\
0\end{array}$ & $\begin{array}{c}173.949 \\
3\end{array}$ \\
\hline $\begin{array}{c}\mathrm{NaOH} ; 1: 3 ; \\
2.5\end{array}$ & $\begin{array}{c}25.60 \\
0\end{array}$ & 2.6400 & $\begin{array}{c}3.476 \\
9\end{array}$ & $\begin{array}{c}29.916 \\
2\end{array}$ & $\begin{array}{c}77.44 \\
0\end{array}$ & 0.6000 & $\begin{array}{c}1.231 \\
5\end{array}$ & $\begin{array}{c}173.997 \\
9\end{array}$ \\
\hline $\begin{array}{c}\mathrm{NaOH} ; 1: 4 ; \\
2.5\end{array}$ & $\begin{array}{c}25.50 \\
0\end{array}$ & 2.6400 & $\begin{array}{c}3.490 \\
3\end{array}$ & $\begin{array}{c}29.910 \\
3\end{array}$ & $\begin{array}{c}77.46 \\
0\end{array}$ & 0.6000 & $\begin{array}{c}1.231 \\
2\end{array}$ & $\begin{array}{c}174.022 \\
3\end{array}$ \\
\hline
\end{tabular}

The inter-planar distance $\mathrm{d}_{002}$ for samples of the carbon material after vanadium recovery varies from 3.4636 to $3.4930 \AA$, and $\mathrm{d}_{110}$ from 1.2304 to $1.2333 \AA$. The character of the microstructure of petroleum coke can be judged according to the results of X-ray phase analysis by the ratio of the average height $\mathrm{L}_{c}$ and the average diameter $\mathrm{L}_{\mathrm{a}}$ of crystallites $[34,35]$. In this case, the ratio of $L_{c} / L_{a}$ varies from 0.16 to 0.22 , so petroleum coke has a flattened structure of crystallites because of thermo baric conditions during the formation of petroleum coke.

In the X-ray diffraction patterns of most samples of carbon materials, in addition to the peaks (002) and (110), there is also a peak with the maximum value of the doubled Bragg diffraction angle $2 \theta$ of about $37^{\circ}$, which is not typical for of the crystal lattice of petroleum coke and reflects the content of impurities.

The results of the analysis show that the relative intensity of this peak, which characterizes the content impurities, has a general tendency to decrease with an increase of the duration of the leaching process from 0.5 to 2.5 hours, but with a minimum at 1.5 hours at a ratio of $S: L=1: 4$ and using sulfuric acid or sodium hydroxide as a leaching reagent. The trend to decrease remains at $\mathrm{L}: \mathrm{S}=1: 3$ and others parameters equal, however withno minimum at 1.5 hours. The relative intensity of the peak at $\mathrm{S}: \mathrm{L}=1: 2$ passes through a maximum at 1.5 hours and returns to the original range of values.

The relative intensity of the peak of $37^{\circ}$ at a leaching time of $0.5 \mathrm{~h}$ and a decrease in the content of the leaching reagent $\mathrm{H}_{2} \mathrm{SO}_{4}$ or $\mathrm{NaOH}$ (the $\mathrm{S}: \mathrm{L}$ ratio varies from 1:4 to 1:3 and $1: 2$ ) increases. However, the relative intensity of this peak decreases at 1.5 and 2.5 hours and others parameters the same.

\section{Conclusion}

It was shown that the extraction of vanadium after the leaching process increases with an increase in the ratio of the $\mathrm{S} / \mathrm{L}$ phases and the duration of the process. It was also shown that sulfuric acid is the best leaching agent, although it increases the sulfur content in coke. Alkali is a more selective solvent compared with sulfuric acid.

The highest recovery of vanadium $(80 \%)$ was observed when the process was carried out in the presence of sulfuric acid for 1.5 hours with a phase ratio of $1: 4$. The maximum of vanadium recovery using sodium hydroxide was observed under the same conditions and amounted to $72 \%$.

The obtained crystals of petroleum coke have a turbostract flattened crystal structure, because of the thermobaric conditions for the formation of petroleum coke. 
This work has also shown that petroleum coke is a promising raw material for the production of vanadium at an industrial scale.

This work was carried out as part of the State Assignment "Development of scientific foundations of innovative technologies for processing heavy hydrocarbon raw materials into environmentally friendly motor fuels and new carbon materials with controlled macro- and microstructural organization of mesophase". The study was conducted with the involvement of the laboratory base of the Center for Collective Use of Saint Petersburg Mining University.

\section{Reference}

1. J. Ancheta, HYDRO-MPC technology for heavy oil refining. Journal of Mining Institute 224: 229-234. (2017).

2. A.A. Sukhanov, Yu.E. Petrova, The possibility of recycling valuable associated components of heavy oils while increasing the overall efficiency of their development. Oil and gas geology. Theory and Practice 4: 1-13 (2009).

3. E.A. Mustafina, O.Y. Poletaeva, E.M. Movsumzade, Heavy metal oils and their demetallization. Oil and Gas Chemistry 4: 15-18. (2014).

4. B. Issa, et al. Assessment of possibility of obtaining alloying components in the process of desalting of heavy hydrocarbon raw materials. Part 1. CIS Iron and Steel Review 19: 8-12 (2020).

5. A. F. Akhmetov, et al. The state of vanadium (V) in crude oil and petroleum residues. International Journal of Applied Engineering Research 10(21):42553-42555 (2015).

6. N. A. Mironov, [et al.]. Comparative Study of Resins and Asphaltenes of Heavy Oils as Sources for Obtaining Pure Vanadyl Porphyrins by the Sulfocationite-Based Chromatographic Method. Energy \& Fuels. 32(12): 12435-12446. (2018).

7. N. A. Mironov, et al. Methods for Studying Petroleum Porphyrins. Petroleum Chemistry: 59(10), 1077-1091. (2019).

8. S. G. Yakubova, et al. Distribution of vanadium and vanadyl porphyrins during fractionation of resins of heavy sulfurous oils. Petroleum Science and Technology, 36(16):1319-1324 (2018).

9. D.N. Nukenov, S.A Punanova, Z.G. Agafonova, Metals in oils, their concentration and extraction methods. (Moscow: GEOS, 2001).

10. V.M. Kapustin, V.F. Glagoleva, Physicochemical aspects of petroleum coke formation. Petroleum Chemistry 56(1):1-9 (2016).

11. E. Nazari, et al. Simultaneous recovery of vanadium and nickel from power plant flyash: Optimization of parameters using response surface methodology. Waste Management 34: 2687-2696. (2014).

12. M. V. Tsygankova, et al. The recovery of vanadium from ash obtained during the combustion of fuel oil at thermal power stations. Russian Journal of Non-Ferrous Metals 52(1): 19-23 (2011).

13. H. Tokuyama, et al. Process development for recovery of vanadium and nickel from heavy oil fly ash by leaching and ion exchange. Separation science and technology 38(6): 1329-1344 (2003).

14. R. Navarro, et al. Vanadium recovery from oil fly ash by leaching, precipitation and solvent extraction processes. Waste Management 27: 425-438 (2007). 
15. E. Guibal, et al. Vanadium extraction from fly ash-preliminary study of leaching, solvent extraction, and sorption on chitosan. Separation science and technology journal 38(12): 2881-2899. (2003).

16. R. Parvizi, et al. Hydrometallurgical extraction of vanadium from mechanically milled oil-fired fly ash: analytical process optimization by using Taguchi design method. Metallurgical and materials transactions 43B: 1269-1276 (2012).

17. V.A. Rudko, N.K. Kondrasheva, R.E. Lukonin, The effect of acid leaching parameters on the extraction of vanadium from petroleum coke. Proceedings of $S P b G T I(T U) 42$ : 43-48 (2018).

18. M.R. Tavakoli, S. Dornian, D.B. Dreisinger, The leaching of vanadium pentoxide using sulfuric acid and sulfite as a reducing agent. Hydrometallurgy 141: 59-66. (2014).

19. Y.L. Zhang, L.Q. Yang, X.G. Tian, The effect of sodium sulfate on vanadium leaching From Petroleum coke and surface physical-chemical properties of leaching solution. Petroleum science and technology 33(15): 1492-1498. (2015).

20. S. A. Savchenkov, The research of obtaining master alloys magnesium-gadolinium process by the method of metallothermic recovery. Tsvetnye Metally 5: 33-39 (2019).

21. S.A. Savchenkov, V.Y. Bazhin, V.G. Povarov, Research on the process of gadolinium recovery from the melt of salts on formation of $\mathrm{Mg}-\mathrm{Zn}-\mathrm{Gd}$ master alloys for manufacturing of magnesium and aluminium special-purpose alloys. Non-ferrous Metals 48(1): 35-40. (2020).

22. N.K. Kondrasheva, V.A. Rudko, V.G. Povarov, Determination of sulfur and trace elements in petroleum coke by X-ray fluorescent spectrometry. Coke and Chemistry 60(6): 247-253. (2017).

23. W.L. Bragg, The Structure of Some Crystals as Indicated by Their Diffraction of Xrays. Proceedings of the Royal Society A: Mathematical, Physical and Engineering Sciences 89(610): 248-277. (1913).

24. G. Wulff, Über die Kristallröntgenogramme. PhysikalischeZeitschrift 14: 217-220. (1913).

25. P. Scherrer. Bestimmung der innerenStruktur und der Größe von KolloidteilchenmittelsRöntgenstrahlen. (Berlin, Heidelberg: Springer Berlin Heidelberg. 1912).

26. F.R. Feret, Determination of the crystallinity of calcined and graphitic cokes by X-ray diffraction. The Analyst 123(4): 595-600. (1998).

27. A.D. Badikova, et al. Complex technological solution for recycling of spent sulfuric acid from alkylation of isobutane by olefins. Chemistry and Technology of Fuels and Oils 53(1): 29-37 (2017).

28. X. Fan, The Fates of Vanadium and Sulfur Introduced with Petcoke to Lime Kilns. (Toronto. 2010).

29. C. Song, K. Liu, Z. Gong, Y. Liu, Thermogravimetric analysis of combustion characteristics of coal gangue and petroleum coke mixture. Journal of Physics: Conference Series 1324: 12-77 (2019).

30. P.N. Kuznetsov, et al. Comparison of supramolecular organization of brown coal from different deposits. Chemistry for sustainable development 9: 255-261 (2001).

31. E.A. Belenkov, E.A. Karnaukhov, Influence of crystal dimensions on interatomic distances in dispersed carbon. Physics of the Solid State 41(4): 672-675. (1999). 
32. Y. Zhu, et al. Preparation and Characterization of Coal Pitch-Based Needle Coke (Part I): The Effects of Aromatic Index ( $\left.\mathrm{f}_{\mathrm{a}}\right)$ in Refined Coal Pitch. Energy \& Fuels 33(4): 3456-3464. (2019).

33. Y. Zhu, et al. Preparation and Characterization of Coal Pitch-Based Needle Coke (Part II): The Effects of $\beta$ Resin in Refined Coal Pitch. Energy \& Fuels 34(2): 2126-2134 (2020).

34. A.N. Popova. Crystallographic analysis of graphite by X-Ray diffraction. Coke and Chemistry 60(9): 361-365 (2017).

35. Z.R. Ismagilov, et al. Structural Analysis of Needle Coke. Coke and Chemistry 62(4): 135-142. (2019). 